\title{
Current Evidence Supports Welling as an Outcrop-Related Base Camp
}

\author{
Metin I. Eren (D, Fernando Diez-Martin, G. Logan Miller, Briggs Buchanan, Richard Haythorn, \\ Matthew T. Boulanger, Ashley Rutkoski, Jennifer Bush, James D. Norris, C. Owen Lovejoy, \\ Richard S. Meindl, and Michelle R. Bebber
}

Seeman, Morris, and Summers misrepresent or misunderstand the arguments we have made, as well as their own previous work. Here, we correct these inaccuracies. We also reiterate our support for hypothesis-driven and evidence-based research.

Keywords: North American archaeology, Paleoindians, Clovis, lithic technology, microwear, experimental archaeology, Ohio, Welling

Seeman, Morris y Summers han confundido o distorsionado tanto nuestros argumentos como su anterior trabajo. Aquí corregimos sus inexactitudes y reiteramos nuestro apoyo a la investigación fundamentada en hipótesis y basada en evidencias.

Palabras clave: arqueología de Norteamérica, paleoamericanos, Clovis, tecnología lítica, huellas de uso, arqueología experimental, Ohio, Welling

$\mathrm{W}$ thank Mark Seeman, Larry Morris, and Garry Summers for their comment (Seeman et al. 2021). However, we are disappointed that their portrayal of our report was not in accordance with our content or intentions. Our arguments are fully presented in two articles presenting multiple lines of evidence that Welling is an outcrop-related base camp (Diez-Martin et al. 2021; Miller et al. 2019). An accurate understanding of our arguments - and even their own previous published work (Seeman et al. 1994)—cannot be deduced from their comment, and we therefore strongly encourage readers to consult relevant literature on Welling and its interpretation (Diez-Martin et al. 2021; Gardner 1977, 1983; Lepper 1986, 2005a, 2005b; Miller et al. 2019; Prufer and Wright 1970; Seeman et al. 1994). Here, we call attention to Seeman and colleagues' (2021) misrepresentations of our argument and set the record straight.

First, Seeman and colleagues (2021) report that we call Welling a "collector-like base camp." To the contrary, we state that Welling is

Metin I. Eren (meren@ kent.edu, corresponding author) D Department of Anthropology, Kent State University, Kent, OH, USA; Department of Archaeology, Cleveland Museum of Natural History, Cleveland, OH, USA

Fernando Diez-Martin — Department of Prehistory and Archaeology, University of Valladolid, Valladolid, Spain

G. Logan Miller Department of Sociology and Anthropology, Illinois State University, Normal, IL, USA

Briggs Buchanan and Richard Haythorn $\square$ Department of Anthropology, University of Tulsa, Tulsa, OK, USA

Matthew T. Boulanger $\square$ Department of Anthropology, Southern Methodist University, Dallas, TX, USA

Ashley Rutkoski - ASC Group, Inc., Columbus, OH, USA

Jennifer Bush $\mathbf{a}$ Johnson-Humrickhouse Museum, Coshocton, OH, USA

James D. Norris, C. Owen Lovejoy, Richard S. Meindl, and Michelle R. Bebber $\square$ Department of Anthropology, Kent State University, Kent, OH, USA

American Antiquity 86(4), 2021, pp. 867-870

Copyright $\odot$ The Author(s), 2021. Published by Cambridge University Press on behalf of

the Society for American Archaeology. This is an Open Access article, distributed under the terms of the Creative Commons Attribution licence (https://creativecommons.org/licenses/by/4.0/), which permits unrestricted re-use, distribution, and reproduction in any medium, provided the original work is properly cited.

doi:10.1017/aaq.2021.116 
an "outcrop-related base camp" within a "collector-like mobility strategy" (Diez-Martin et al. 2021:186). Indeed, we use the term "outcrop-related base camp" 33 times in our two cited articles. As Miller and colleagues (2019) make clear, Gardner's (1977) definition of an "outcrop-related base camp" differs from Seeman and colleagues' (2021, citing Binford 1980) definition of a "collector-like base camp." Our terminology therefore contains no Binfordian connotations associated with collector base camps, but it still emphasizes Clovis logistic mobility that characterizes a "collectorlike mobility strategy" (Diez-Martin et al. 2021; Miller et al. 2019:67). Perhaps Seeman and colleagues (2021) misread our work, or they assume that only Binford's terms and concepts are valid for archaeological explanation.

Second, Seeman and colleagues (2021) misrepresent their own (1994) interpretation of Welling's Clovis occupation. They state that they refer to the site as a "quarry-related, manufacturing camp" (1994:83) although elsewhere they refer to it as a "workshop" (Seeman et al. 1994:79, 81). Although it is true that they employ the term "quarry-related, manufacturing camp" (Seeman et al. 1994), they nevertheless fail to relate it to their definition of one, which is as follows. They state that "bands or task groups came to the Welling site from elsewhere mainly to retool" (1994:81; emphasis added). Nowhere do Seeman and colleagues (1994) state that "ancillary activities" occurred at Welling, as Seeman and colleagues (2021) now allege. Moreover, Seeman and colleagues (1994) directly contrasted Welling with Nobles Pond, a multipleactivity area base camp, and then concluded that "a comparison of the finished to unfinished fluted bifaces at the three sites [Welling, Nobles Pond, and Sandy Springs] makes clear the distinctive nature of the Welling site as a workshop" (Seeman et al. 1994:81; emphasis added). As both Miller and others (2019) and Diez-Martin and others (2021) explain, this is precisely why Seeman and colleagues' (1994) published interpretation of Welling as a lithic "workshop" differs categorically from Lepper's (1986, 2005a, 2005b), who interpreted the site more along the lines of Gardner's (1977) "outcrop-related base camp." Among several differences between these two types of sites-lithic workshop and outcroprelated base camp-is their role in the overall settlement and mobility system. The outcroprelated base camp serves as a hub or core; the lithic workshop is located at the end of a spoke radiating out from this nucleus (Diez-Martin et al. 2021; Eren et al. 2015, 2019; Lepper 1986, 2005a, 2005b; Meltzer 2009, 2021; Miller et al. 2019; Sholts et al. 2012; Waters et al. 2011).

Moreover, Miller and colleagues' (2019) microwear study and Diez-Martin and colleagues' (2021) experimental study specifically tested these contrasting hypotheses of Seeman and colleagues (1994) and Lepper (1986, 2005a, 2005 b), and not our own "new reinterpretation" as Seeman and colleagues (2021) claim (i.e., we did not erect their work as a "straw man" to bolster our own hypothesis). Instead, our intent was to evaluate two mutually exclusive hypotheses to determine which was most consistent with available evidence.

Third, Seeman and colleagues (2021) state that only $24 \%$ of the fluted bifaces from Welling were finished products and that we failed to discuss this fact. This is true. Nowhere did we state that more than $24 \%$ of the fluted bifaces were finished products. Instead, we stated that "an observational study by Seeman and others (1994:81) suggested to them that over $75 \%$ of the fluted points at Welling were broken during manufacture" (Miller et al. 2019). We somewhat naively assumed that readers would understand that if more than $75 \%$ of bifaces were broken during manufacture, then the remaining approximately $25 \%$ did not suffer that fate and therefore were finished products. Returning to our previous reference to Gardner's work, he states that one of the criteria for an "outcrop-related base camp" is "numerous discarded and broken bifaces from middle to final form reduction stages and few completed projectile points" (Gardner 1977:49). We appreciated this opportunity to point to this additional evidence, which is consistent with the interpretation of Welling as an outcrop-related base camp.

Fourth, Seeman and colleagues (2021) make statements that appear to contravene the interpretation of Welling as an outcrop-related base camp but in fact do not. For example, they state that "micro-worn tools used elsewhere on the 
landscape may be shed at manufacturing camps [i.e., lithic workshops] where the replacement of entire toolkits has been planned in advance" (865). But micro-worn tools used elsewhere on the landscape may also be shed at outcrop-related base camps as well. Seeman and colleagues (2021) also state that "place is often the best predictor of site functionality," and given that high-quality flint is nearby, Welling is likely a lithic workshop. But by definition, an outcroprelated base camp must be located at a place with flint nearby.

Fifth, Seeman and colleagues (2021) state that the conclusion of Diez-Martin and others (2021) "shows only two results" (emphasis added). This is correct. To distinguish between two alternative hypotheses, we created an experimental model for comparison with the archaeological record, and from which clear predictions could be made about mean flake size and flake size variability to test each hypothesis. Seeman and colleagues (2021) state that our predictions are "counterintuitive." Why? They do not explain. We, however, explained why our scientific predictions and results discriminated between Seeman and colleagues' (1994) and Lepper's (1986, 2005a, 2005b) different interpretations, and we provided an extended discussion of future tests, experimental variables, caveats, and the like so that our current results could be either further supported or questioned.

Sixth, Seeman and colleagues (2021) suggest that the experimental bifaces from which we derived our experimental model were "simply too small," a "prospect we do not consider." This is simply untrue. Diez-Martin and colleagues write,

A fourth possible reason that the Welling and experimental assemblages were significantly different could be a result of core size and shape. Larger core sizes, or different core shapes, may yield different bifacial flake debitage size distributions. Here, we were intentionally explicit and specific in what we tested in that our experimental core sizes were based on what is actually present in the archaeological record at Welling. Although it is a good starting point, a greater variety of core sizes and shapes can be, and should be, examined in the future [2021:192].
To conclude, it is worth noting, as both Gardner (1977) and Miller and others (2019) point out, that although site types serve a heuristic purpose, the reality of archaeological sites can be less apparent. We must therefore examine multiple lines of evidence and assess where their preponderance lies. Currently, our two structured, hypothesis-constructed studies (Diez-Martin et al. 2021; Miller et al. 2019) favor an interpretation of Welling as an outcrop-related base camp, where people lived, manufactured tools, left and returned to again and again, gathered together, feasted, played, shared stories, and mourned lost friends (Lepper 2005b) — rather than a lithic workshop where people "came from elsewhere mainly to retool" (Seeman et al. 1994). But although the current preponderance of evidence points to Welling being an outcrop-related base camp, we acknowledge that not all future fieldbased or collections-based research may support that interpretation. We encourage others to formally construct and test hypotheses about Welling, and not merely maintain existing ones for which evidence is found to be lacking.

Acknowledgments. We are very appreciative to American Antiquity editor Debra Martin for reaching out to us, and for her assistance and support while we wrote this response. We are also grateful to our Kent State Anthropology Chair Mary Ann Raghanti, who read an early draft of this manuscript, and the rest of the current Kent State Anthropology Department faculty for their unwavering support and enthusiasm for our research. This research was supported by the Kent State University College of Arts and Sciences as well as the Robert J. and Lauren E. Patten Endowment, which will support archaeological research at Kent State in perpetuity.

Data Availability Statement. No original data were used.

\section{References Cited}

Binford, Lewis R.

1980 Willow Smoke and Dogs' Tails: Hunter-Gatherer Settlement Systems and Archaeological Site Formation. American Antiquity 45:4-20.

Diez-Martin, Fernando, Briggs Buchanan, James D. Norris, and Metin I. Eren

2021 Was Welling, Ohio (33-Co-2), a Clovis Basecamp or Lithic Workshop? Employing Experimental Models to Interpret Old Collections. American Antiquity 86:183-198.

Eren, Metin I., Briggs Buchanan, and Michael J. O’Brien

2015 Social Learning and Technological Evolution during the Clovis Colonization of the New World. Journal of Human Evolution 80:159-170.

Eren, Metin I., G. Logan Miller, Briggs Buchanan, Matthew T. Boulanger, Michelle R. Bebber, Brian G. Redmond, 
Lisa Coates, Patricia Boser, Becky Sponseller, and Matt Slicker

2019 The Black Diamond Site, Northeast Ohio, USA: A New Clovis Occupation in a Proposed Secondary Staging Area. Journal of Paleolithic Archaeology 2:211-233.

Gardner, William

1977 Flint Run Paleoindian Complex and Its Implications for Eastern North American Prehistory. Annals of the New York Academy of Sciences 288:257-263.

1983 Stop Me If You've Heard This One Before: The Flint Run Paleoindian Complex Revisited. Archaeology of Eastern North America 11:49-64.

Lepper, Bradley T.

1986 Early Paleo-Indian Land Use Patterns in the Central Muskingum River Basin, Coshocton County, Ohio. PhD dissertation, Department of Anthropology, Ohio State University, Columbus.

2005a Pleistocene Peoples of Midcontinental North America. In Ice Age Peoples of North America: Environments, Origins, and Adaptations of the First Americans, edited by Robson Bonnichsen and Karen L. Turnmire, pp. 362-394. Center for the Study of the First Americans, Corvallis, Oregon.

2005b Ohio Archaeology: An Illustrated Chronicle of Ohio's Ancient American Indian Cultures. Orange Frazer Press, Wilmington, Ohio.

Meltzer, David J.

2009 First Peoples in a New World. University of California Press, Berkeley.

2021 First Peoples in a New World. 2nd ed. University of Cambridge Press, Cambridge.

Miller, G. Logan, Michelle R. Bebber, Ashley Rutkoski, Richard Haythorn, Matthew T. Boulanger, Briggs Buchanan, Jennifer Bush, C. Owen Lovejoy, and Metin I. Eren
2019 Hunter-Gatherer Gatherings: Stone-Tool Microwear from the Welling Site (33- Co-2), Ohio, USA, Supports Clovis Use of Outcrop-Related Base Camps during the Pleistocene Peopling of the Americas. World Archaeology 51:47-75.

Prufer, Olaf H., and Norman L. Wright

1970 The Welling Site (33Co-2): A Fluted Point Workshop in Coshocton County, Ohio. Ohio Archaeologist 20(4):259-268.

Seeman, Mark F., Larry Morris, and Garry L. Summers

2021 Purpose at Welling: Additional Considerations Regarding Interpretation. American Antiquity 86:864 866.

Seeman, Mark, Garry Summers, Elaine Dowd, and Larry Morris

1994 Fluted Point Characteristics at Three Large Sites: The Implications for Modeling Early Paleoindian Settlement Patterns in Ohio. In The First Discovery of America: Archaeological Evidence of the Early Inhabitants of the Ohio Area, edited by William S. Dancey, pp. 77-93. Ohio Archaeological Council, Columbus.

Sholts, Sabrina B., Dennis J. Stanford, Louise M. Flores, and Sebastian K. T. S. Wärmländer

2012 Flake Scar Patterns of Clovis Points Analyzed with a New Digital Morphometrics Approach: Evidence for Direct Transmission of Technological Knowledge across Early North America. Journal of Archaeological Science 39:3018-3026.

Waters, Michael, Charlotte Pevny, and David Carlson

2011 Clovis Lithic Technology: Investigation of a Stratified Workshop at the Gault Site, Texas. Texas A\&M University Press, College Station.

Submitted August 31, 2021; Accepted September 1, 2021 